\title{
Development of deep-sea drone by spherical ultrasonic motor
}

\author{
S. Toyama ${ }^{1}$, U. Nishizawa ${ }^{2}$, O. Matsubara ${ }^{3}$ \\ ${ }^{1,2}$ Tokyo Noko University of Technology, Koganei, Tokyo, Japan \\ ${ }^{3}$ QI Inc., Fukuura, Kanazawa, Yokohama, Japan \\ ${ }^{1}$ Corresponding author \\ E-mail: ${ }^{1}$ toyama@cc.tuat.ac.jp, ${ }^{2}$ n-uichi@cc.tuat.ac.jp, ${ }^{3}$ matsubara@qi-inc.com
}

Received 15 August 2018; accepted 27 August 2018

DOI https://doi.org/10.21595/vp.2018.20142

Check for updates

Copyright $\mathbb{C} 2018$ S. Toyama, et al. This is an open access article distributed under the Creative Commons Attribution License, which permits unrestricted use, distribution, and reproduction in any medium, provided the original work is properly cited.

\begin{abstract}
The world ocean occupies $70 \%$ on the earth and the average sea depth is about 4,000 m. More than 80 percent of it has not been investigated precisely and the bottom shape of the sea has not been mapped. When doing resource-searching in the future, the precise maps must be required. So, the authors have developed a drone movable around 4,000 $\mathrm{m}$ deep sea to measure the bottom of the ocean. It is based on spheres, which includes cameras, batteries, some sensors and controllers. It can rotate a spherical rotor sensing widely to obtain the information about the bottom of the sea. At the first step of the research, the authors have made basic experiments of the motor's performance in water. The authors have obtained the excellent results in maneuverability, temperature durability, and shock resistance of the motor.
\end{abstract}

Keywords: ultrasonic motor, waterproof, drone.

\section{Introduction}

The purpose of this research is to make a map of the bottom of the sea all over the world. At the present, only 15 percent of it has been measured and mapped. However, it is only shallow sea around the continents or islands and the rest is unknown. In the deep sea, there may be four times as much as rare metal, hydrothermal deposits and manganese nodule comparing to the land. In the future, the precise maps will be necessary when mining them. Generally speaking, in order to make sea maps, the research ships have used ultrasonic technology to survey the sea bottom by detecting reflecting waves, but its accuracy is poor, and it cannot be used for resource searching. To make the precise maps, it requires deep-sea submarines movable around 4,000 $\mathrm{m}$ deep sea. However, they are very expensive, and they can measure very narrow area at once. To cover all deep sea, inexpensive submarines are necessary.

Since several hundred atmospheric pressure is applied in the deep sea, the resistance shape is only sphere to support the pressure in disperse. So, all mobilities in the deep sea should be based on sphere in design. So, the authors have proposed the deep-sea drone by spherical ultrasonic motors. It has advantages as follows:

1) It has only spherical rotor and three ring type stators. Simple structure and easy maintenance. Low cost. Easy use of group robots (several hundreds of drones are available at reasonable cost).

2) Rotational spherical rotor with sensors covers wide area.

\section{Concept of deep-sea drone}

\subsection{Spherical ultrasonic motor}

An ultrasonic motor is a kind of friction motor. If frictional force has been kept in water, it will work well. Adding that, its structure is very simple. It consists of a ring type elastic body with piezoelectric ceramics (stator) and a rotor [1-4]. A spherical ultrasonic motor is an application by three stators and a spherical rotor (Fig. 1) [5, 6]. The control is easy by phase differences of applied voltages to each piezoelectric ceramics. It has advantages; three rotational degrees of freedom, 
simple structure, no reduction gears (high torque and low speed characteristics), short response time, no braking mechanism at rest, and little affected by magnetic or current field.

\subsection{Concept of deep-sea drone with spherical ultrasonic motors}

The image of a deep-sea drone is shown in Fig. 2. It has four spherical ultrasonic motors. The two motors at the top of the drone are rotating with cameras, batteries and computers. The middle motor is at rest and has some batteries for driving other motors, GPS, accelerometers, computers and an iridium mobile phone. The last motor is promoting the drone by rotating propeller. It can also control the direction of the propeller. All motors' stators are connected to the middle sphere's battery by the cables specially made for deep sea. All motors can communicate by Wi-Fi (the distance to each motor is just about $1 \mathrm{~cm}$ ).

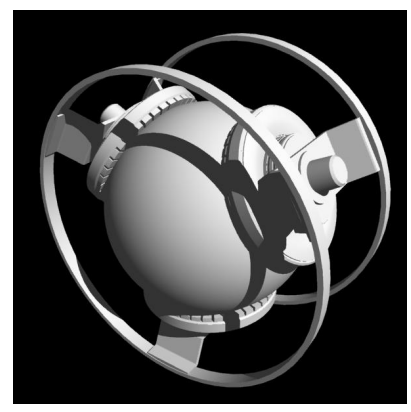

Fig. 1. Overview of spherical ultrasonic motor

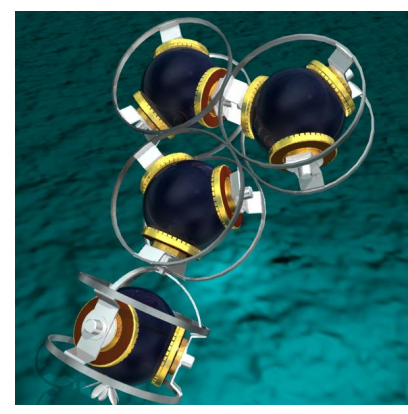

Fig. 2. Deep-sea drone

\section{Driving in water}

The authors have researched ultrasonic motor driving in water previously [6]. In the research, using TR motor (motor with two degree of freedom of Translational and Rotational movement in one joint), the authors have succeeded in driving it in water. It should have sealant materials on electrodes and keep firm contact of the stator and the rotor in water; that is to say, it is necessary to eliminate the water film between them to transmit force from the stator to the rotor by contact. The authors have applied knurled rotor to prevent the thin water film and pasted silicone rubber to the electrodes to obtain good rotational and translational movement in water.

Based on the previous research, the authors have sprayed poly vinyl resin to electrodes, the spherical rotor (plastic ball) and the stator. It is because it makes a very thin film and no disturbance to rotate a spherical rotor.

First, the authors have measured impedance about one pair of the rotor and the stator. The results are shown in Fig. 3. It shows that it has the clear resonant frequencies in water. It shows possibility of moving in water. Comparing to the case of driving in the air, the resonant frequency shifts to the lower side by 3 or $4 \mathrm{kHz}$ due to additional water mass effect, that is, the vibration of the stator moves with the surrounding water.

Next, the authors have investigated the rotor materials. Since the rotor material requires adequate elasticity and mass, the authors have compared some kinds of resins. The experiment results show that the resonant and anti-resonant frequencies of the stator are not clear, but observed. This is because resin spheres are relatively light and affected by floating force in water, and the contact force between the stator and the rotor is decreasing.

Based on these experiment results, the authors have made experiments of rotating the spherical ultrasonic motor in water successfully with sealant coated stators and resin spheres. It shows good maneuverability in water.

In the experiments so far, the higher voltage should be applied to amplify the vibration (the amplitude of vibration of the stator is depressed in water) and adequate waterproof should be 
treated in order to work in water.

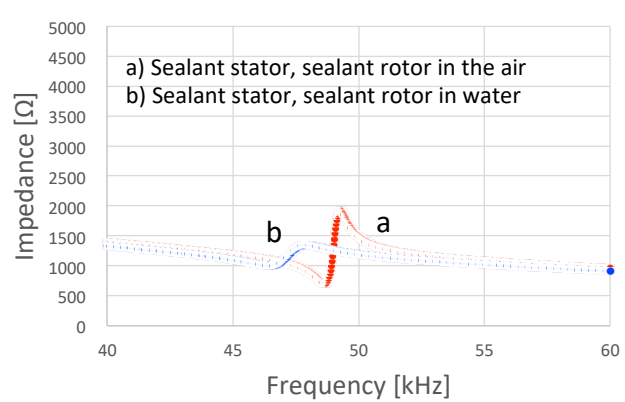

a)

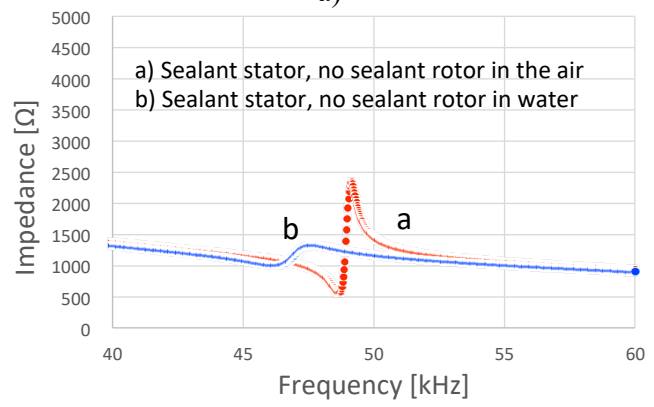

c)

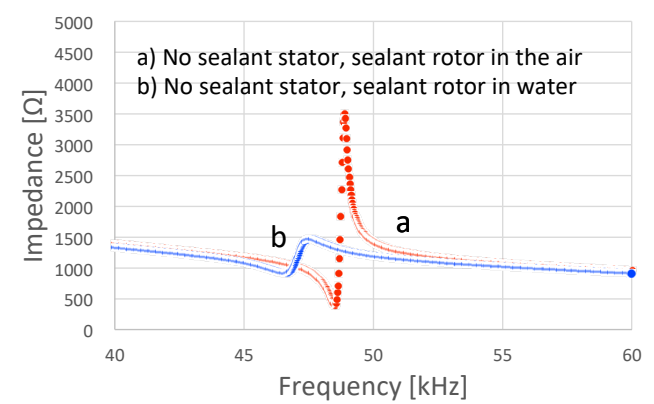

b)

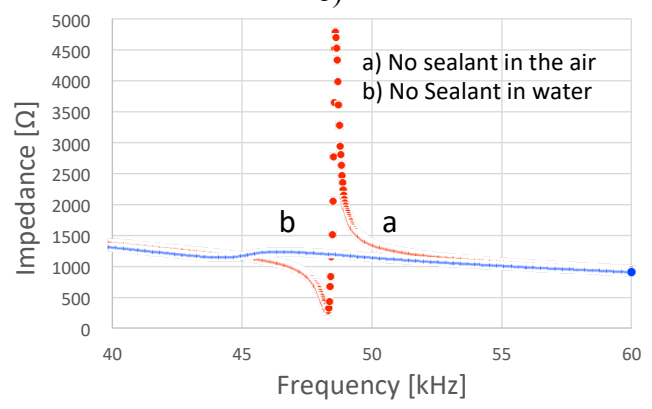

d)

Fig. 3. Impedance of stators with and without sealant

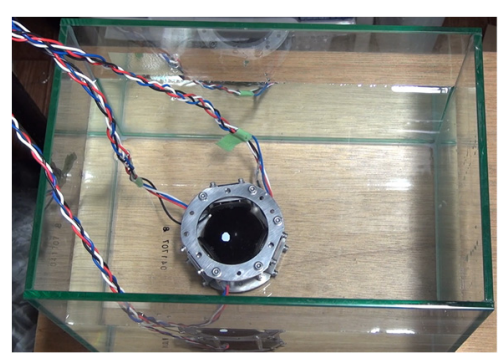

a)

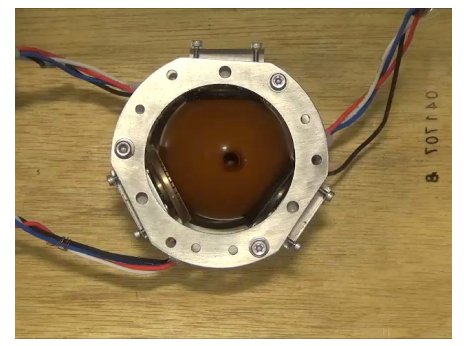

b)

\begin{tabular}{c|c}
\hline Applied voltage & $370 \mathrm{Vp}-\mathrm{p}$ \\
\hline Resonant frequency & $45.5 \mathrm{kHz}$ \\
\hline Phase difference & $90^{\circ}$ \\
\hline Rotational speed & $30 \mathrm{rpm}$ \\
\hline
\end{tabular}

Fig. 4. Spherical ultrasonic motor in water

\section{Durability about the temperature of environment}

There are some places where the sea temperature reaches to $200{ }^{\circ} \mathrm{C}$ or $300{ }^{\circ} \mathrm{C}$ such as hydrothermal deposits and sea volcanoes. Therefore, the spherical ultrasonic motor has to be durable for the high temperature environment. The piezoelectric element and the glue are likely to get damage by high temperature. So, the authors have examined closely the piezoelectric element materials durable for high temperature, that is, the Curie point should be more than $300{ }^{\circ} \mathrm{C}$. Besides that, the authors have researched it about the electromechanical coupling coefficient to show the rate of efficiency from electrical input to the mechanical energy, the mechanical quality coefficient to show small loss of elastic deformation and the piezoelectric constant to show the rate of the distortion of the piezoelectric element by an electric field. The authors have chosen the piezoelectric element \#N6 of Tokin Co. It has high Curie point $325^{\circ} \mathrm{C}$ and excellent characteristics of electromechanical coupling coefficient, mechanical quality and elastic deformation loss.

The authors have also investigated the high temperature durable glue. However most of the commercially available glues have low glass transition point. So, as a moderated even a little 
material, the authors have chosen one-component epoxy adhesive \#TB2285 of ThreeBond Co. to show the $125{ }^{\circ} \mathrm{C}$ glass transition point, non-conductivity, the high detached bonding strength, good adhesive strength and excellent hardness. The authors have evaluated this piezoelectric ceramics and the glue. The results are shown in Fig. 5. It shows that the motor keeps movable due to maintaining piezoelectricity within $120^{\circ} \mathrm{C}$.

The experiments have shown that it is working for $90 \mathrm{~min} 30 \mathrm{sec}$ in $120{ }^{\circ} \mathrm{C}$ environments. When driving it in higher temperature environment, working time may be shorter. However, short working time may be sufficient since the temperature of the motor does not go up suddenly around hydrothermal deposits. It may be sufficient time for taking photos and measuring the sea bottom shape.

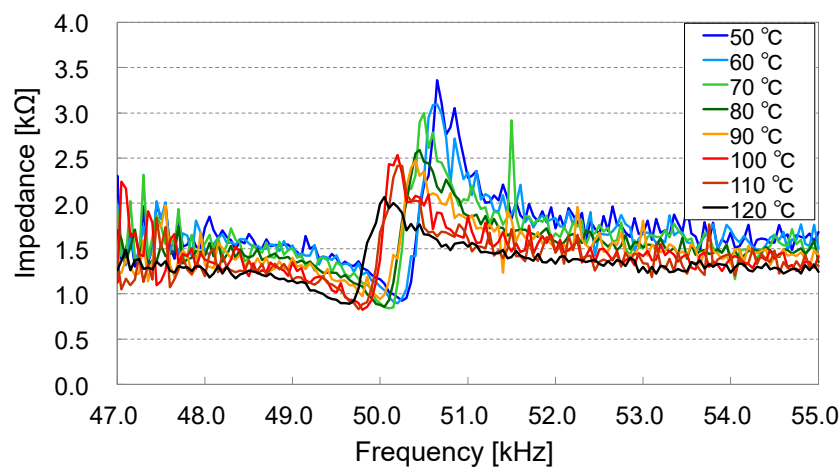

Fig. 5. Impedance temperature characteristics
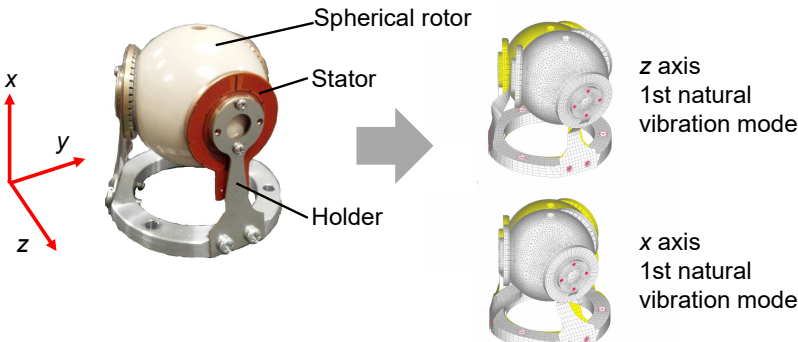

Finite element method

NX Nastran ver.9.0 Number of elements: 104,871 Number of nodes: $\quad 163,411$ Natural vibration analysis $x$ : 1st natural frequency: $1422.64 \mathrm{~Hz}$ $y$ : 1st natural frequency: $598.54 \mathrm{~Hz}$ z: 1st natural frequency: $598.71 \mathrm{~Hz}$

Fig. 6. Vibration analysis by FEM

Half sine shock

\begin{tabular}{c|c|c}
\hline & Time [ms] & Max acceleration [G] \\
\hline$z$ & 5 & 20 \\
\hline$x$ & 5 & 20 \\
\hline & Time [ms] & Max acceleration [G] \\
\hline$z$ & 11 & 30 \\
\hline$x$ & 11 & 30 \\
\hline$z$ & Time [ms] & Max acceleration [G] \\
\hline$z$ & 11 & 40 \\
\hline$x$ & 11 & 40 \\
\hline
\end{tabular}

$z$ axis direction

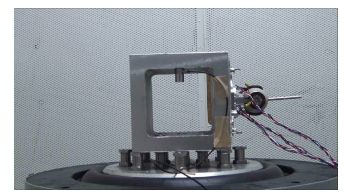

$x$ axis direction

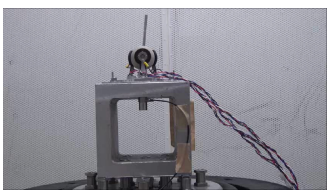

Fig. 7. Impact experiments 


\section{Durability about the vibration and impact}

The spherical ultrasonic motor gets damage, or the rotor jumps out from the holder due to the vibration or impact when conveying it or throwing it to the sea. To evaluate it, the authors have modeled it by finite element method (NX Nastran). The results are shown in Fig. 6. The first natural frequencies are more than $100 \mathrm{~Hz}$ to imply no need of careful operation ordinarily.

However, when it gets serious impact in case of collision of the drones with each other or impact with bottom, it may become serious problems. So, the authors have made experiments about impact as follows.

1) Applied half sin curve with max acceleration $20 \mathrm{G}, 5 \mathrm{msec}$ (half cycle time) along $x$ axis and $z$ axis.

2) Applied half sin curve with max acceleration $30 \mathrm{G}, 11 \mathrm{msec}$ (half cycle time) along $x$ axis and $z$ axis.

3) Applied half sin curve with max acceleration $40 \mathrm{G}, 11 \mathrm{msec}$ (half cycle time) along $x$ axis and $z$ axis.

In the cases of 1) and 2), the motor has firmly kept the rotor inside, but in the case of 3), the rotor has jumped out. The rotor had some dimples. But it shows normal rotation after impact, and the screws and the holder have no damages.

The stopper is necessary to prevent it (Fig. 8). In the sea, the impact may not be serious due to damping effect by the fluid, but the stopper is indispensable in case of serious accidents.

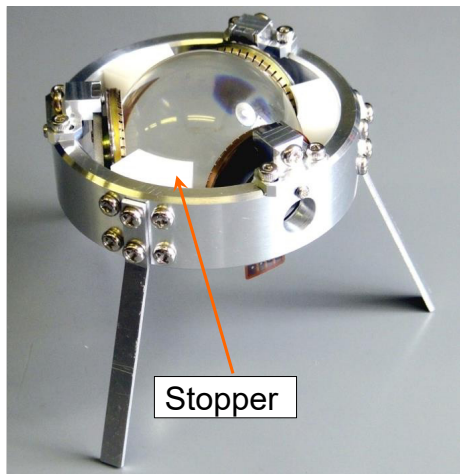

Fig. 8. Spherical motor with stoppers

\section{Conclusions}

The authors have obtained conclusions as follows.

1) The spherical ultrasonic motor shows good maneuverability in water.

2) The spherical ultrasonic motor is durable for $120^{\circ} \mathrm{C}$ environments.

3) The spherical ultrasonic motor has the stopper to prevent the rotor's jumping out from the holder. It is durable for the vibration and impact when ordinary dealing.

The authors have shown the possibility of deep-sea drone by spherical ultrasonic motor successfully.

\section{Acknowledgement}

Funding from Leave a Nest Co., Ltd. is gratefully acknowledged.

\section{References}

[1] Ferreira P. A. M. High-performance load-adaptive speed control for ultrasonic motors. Control Engineering Practice, Vol. 6, Issue 1, 1998, p. 1-13. 
[2] Hoshina M., Mashimo T., Fukaya N., Matsubara O., Toyama S. Spherical ultrasonic motor drive system for pipe inspection. Advanced Robotics, Vol. 27, Issue 3, 2013, p. 199-209.

[3] Mashimo T., Toyama S. Vibration analysis of cubic rotary-linear piezoelectric actuator. IEEE Transactions on Ultrasonics, Ferroelectrics, and Frequency Control, Vol. 58, 2011, p. 844-847.

[4] Nishizawa U., Oohashi T., Toyama S. Evaluation of spherical ultrasonic motor for space in low temperature condition. Journal of Vibroengineering, Vol. 19, Issue 7, 2017, p. 5170-5181.

[5] Nishizawa U., Oohashi T., Toyama S. Evaluation of resistance against vibration and shock resistance on spherical ultrasonic motor. Journal of Modeling and Optimization, Vol. 8, Issue 2, 2018, p. 68-73.

[6] Toyama S., Nishizawa U. Waterproof ultrasonic motor. Vibroengineering Procedia, Vol. 11, 2017, p. $52-55$. 